\title{
O acontecimento João de Deus e os enquadramentos na mídia televisiva
}

\section{The event João de Deus and the frameworks in the television media}

Marcos Vinicius Meigre e Silva ${ }^{1}$ 


\section{Resumo}

Este artigo analisa a construção de sentidos, o acionamento de valores sociais e os posicionamentos assumidos pelos sujeitos em torno do caso de denúncias contra o médium João de Deus. Tomando por objeto empírico o programa Fantástico, da TV Globo, analiso três edições a fim de captar as fases do acontecimento e suas reverberações na televisão. A partir das análises, foi possível apreender tensionamentos em torno dos papéis sociais "pai", "médium" e "criminoso", bem como os valores evocados para cada um destes elementos. Por fim, o acontecimento já em fase de normalização se consagra numa espécie de compensação simbólica com a manutenção da prisão do médium.

Palavras-chave

Religião, telejornalismo, acontecimento.

\section{Abstract}

This article analyzes the construction of meanings, the activation of social values, and the positions assumed by the subjects around the reports against the medium João de Deus. Taking as empirical object TV Globo's program, Fantástico, I analyze three issues in order to capture the phases of the event and their reverberations in television. The analysis explains the tensions around the social roles of "father", "medium" and "criminal", as well as the values evoked for each of these elements. Lastly, the event, already under a normalization process, is consecrated in a kind of symbolic compensation with the maintenance of the medium's inprisonment.

\section{Keywords}

Religion, telejournalism, event. 
Na noite de 7 de dezembro de 2018, o programa Conversa com Bial, da TV Globo, exibiu entrevistas com mulheres que fizeram acusações contra o médium João Teixeira de Faria (mundialmente conhecido como João de Deus) por abuso sexual. Dentre as dez brasileiras entrevistadas, quatro tiveram seus depoimentos levados ao ar, e em estúdio estava a holandesa Zahira Lienike Mous - a única que aceitou exibir o próprio rosto. As descrições e comentários feitos pelas mulheres despertavam horror e indignação, esboçados nas reações do apresentador em alguns instantes do programa de TV. Logo, obviamente, as repercussões vieram à baila e tomaram conta da pauta de outros produtos da emissora, bem como da mídia jornalística em geral - no Brasil e no exterior.

O programa Fantástico daquele fim de semana, em 9 de dezembro de 2018, após a exibição da vinheta de abertura, dedicou treze minutos para repercutir o caso em uma grande reportagem. O acontecimento descortinado pela entrevista das mulheres a Pedro Bial rendeu uma série de debates e, na semana seguinte, em meio às repercussões do caso, João de Deus estava foragido da justiça goiana, entregando-se à polícia no domingo. Esse fato encabeçou a edição do dominical também em 16 de dezembro de 2018 e dominou os primeiros 25 minutos da atração, divididos entre grande reportagem e inserções ao vivo de repórter em frente à delegacia para a qual o médium fora conduzido.

Passadas semanas, o assunto não abandonou a pauta jornalística, mas entrou em rota de esfriamento, com atualizações pontuais sobre o avançar das investigações, os depoimentos das mulheres, o estado de saúde do médium preso e as ações da defesa. Até que, em 24 de março de 2019, o Fantástico fez ebulir novamente o debate em torno da figura de João de Deus, trazendo uma longa reportagem de 16 minutos sobre acusações de lavagem de dinheiro, contrabando de minério radioativo e assassinatos a ele atribuídos. O material, resultado de um jornalismo investigativo desenvolvido durante três meses, traçou planos de ação de João de Deus, modos de lidar com inimigos locais, denúncias recebidas ao longo da vida e inquéritos arquivados. A irrupção das acusações contra o médium instaurou um cenário de desorganização em torno 
de sua imagem pública e o acontecimento nos leva a refletir sobre os sentidos acionados em torno deste debate.

Por estas razões, o presente trabalho investiga o acontecimento João de Deus, identificando os quadros de sentido, os posicionamentos dos sujeitos e as interações estabelecidas em reportagens exibidas pelo dominical Fantástico, tomando para composição do corpus analítico as três edições descritas. Assim, busco entrever o acontecimento desde sua fase de irrupção - e imediata descrição até o momento de normalização. Para investigá-lo neste trabalho, no entanto, me amparo na noção de acontecimento articulada aos enquadramentos a fim de captar as evocações em torno de João de Deus. Entendo aqui acontecimento como um operador metodológico de importante contribuição para o campo da comunicação (FRANÇA; LOPES, 2017). Para esta empreitada, na seção seguinte abordo o conceito de acontecimento e suas singularidades enquanto aporte para as pesquisas da comunicação. Na sequência, trago breves ponderações sobre a noção de enquadramento e footing, a fim de articulá-las aos preceitos acontecimentais, bem como uma sintética apresentação da celebridade religiosa em foco e, após estas incursões, seguem-se as análises desenvolvidas a partir do acontecimento João de Deus.

\section{O acontecimento como operador teórico-metodológico para a comunicação}

O emprego do termo "acontecimento" é, para a comunicação, uma questão de forte envergadura teórico-conceitual. Não se trata, portanto, de uma palavra utilizada sem arcabouço epistemológico. Antes de se tornar um termo robusto para nosso campo, investigações sobre acontecimentos já pairavam em outras áreas do saber tais como a história e a filosofia. Entendido como uma irrupção na continuidade da vida, o acontecimento nos instiga a falar sobre ele (MOUILLAUD, 2002), de tal modo que "interrompe uma rotina, atravessa o já esperado e conhecido, se faz notar por aqueles a quem ele acontece" (FRANÇA, 2012, p. 13). Nesta perspectiva, é fundamental reconhecer sua capacidade de desorganização do presente, instaurando uma descontinuidade: 
São descontínuos relativamente a uns e a outros e excedem as possibilidades previamente calculadas, rompem com a seriação da conduta ou do correr das coisas - há seriação quando os actos ou os acontecimentos anteriores da série abrem a via aos seguintes, de tal forma que estes resultam dos que o precederam. Esta descontinuidade provoca surpresa e afecta a continuidade da experiência porque a domina. (QUÉRÉ, 2005, p. 4)

Essa é a perspectiva hermenêutica de Quéré (2005), que não se reduz a tratar como sinônimos fato e acontecimento, tampouco limita acontecimento ao âmbito das análises linguísticas, levando-o para o domínio da experiência, da afetação e da passibilidade - ou seja, do poder de afetação intrínseco a um acontecimento. Quéré (2005) defende o acontecimento como um processo hermenêutico graças a sua capacidade de convocar causas, mas também evocar revelações em torno de si, a fim de ser compreendido. Nesse sentido:

Acontecimento, numa perspectiva pragmatista, refere-se a uma ocorrência, um fato concreto do cotidiano com grande poder de afetação, que suscita inquietações, demanda escolhas e provoca ações, este fato convoca e revela sentidos, que dizem da sociedade na qual ele ocorre. (FRANÇA; LOPES, 2017, p. 73-74)

Quando investiga os acontecimentos, à luz da contribuição das mídias, Quéré (2012) fala em acontecimento-existencial e acontecimento-objeto. O primeiro é a ocorrência imediata na ordem da experiência do mundo, sua condição de irrupção sobre a tessitura da cotidianidade; enquanto o segundo ecoa o acontecimento-existencial e o simboliza, dotando-Ihe de novas qualidades e dimensões discursivas - o que constituiria a dupla vida do acontecimento.

Como se pode observar, o acontecimento fomenta a tessitura das temporalidades, pois, na busca por ser compreendido, definido e narrado no tempo presente, ele convoca sentidos em torno de um passado revisitado e descortina variações de futuro (QUÉRÉ, 2005) e é nesta condição processual que um acontecimento deve ser captado. Tais convocatórias, em alusão a Mead (1934), fazem emergir as noções de história e profecia como perspectivas de reflexão relativas ao acontecimento e à interpretação do tempo que o delimita. Ao alargar o campo de possibilidades, ou 
seja, evidenciando um novo campo de possíveis (ARENDT, 2008), um acontecimento carrega consigo um potencial inaugural. Uma das possibilidades de investigação em torno de um acontecimento, a qual adoto neste trabalho, é

[...] analisar os diferentes enquadramentos de um acontecimento, não apenas identificando $o$ ângulo adotado pelas abordagens noticiosas, mas sobretudo percebendo a utilização de quadros de sentido (Goffman, 2012), isto é, a inserção do acontecimento dentro de determinadas configurações, a definição de situações interativas e o posicionamento dos sujeitos no âmbito do acontecimento. (FRANÇA; LOPES, 2017, p. 77)

Em termos de operacionalização do conceito, é importante entender que o acontecimento passa por um processo de individuação - ou individualização (QUÉRÉ, 2005), o que significa dizer que sua singularidade não é dada em si mesma, mas constituída. Nesta dinâmica de diferenciação, podemos apreender um percurso metodológico para o emprego do acontecimento na comunicação. Com base em Quéré, é possível estabelecer alguns passos que delimitam as análises acontecimentais e como se operacionalizar o conceito (FRANÇA, 2011, 2012; FRANÇA; LOPES, 2017). Metodologicamente, o seguinte percurso interpretativo é uma das formas de analisar um acontecimento:

1. Descrição: é o passo inicial que, de fato, identifica a ocorrência, sua inserção no mundo da vida, articulando-se aos quadros de sentido. Erving Goffman (1998, 2012) é basilar neste entendimento, pois, para este autor, os quadros de sentido ajudam a definir as situações e posicionar os sujeitos perante as interações que promovem entre si. "O que está acontecendo aqui?" é o questionamento que os quadros de sentido permitem responder, podendo haver disputas de sentidos entre eles.

2. Narrativização: o acontecimento se insere numa trama composta por intriga, alicerçado numa sequencialidade temporal que o vincula a um passado e a um futuro específicos. Este caráter narrativo envolve compreender as ações dos atores relacionados ao acontecimento. 
3. Identificação do pano de fundo pragmático: diz das práticas, crenças e hábitos que organizam a sociedade em que o acontecimento se deu. Tais valores refletem como os sujeitos se posicionam perante 0 acontecimento, bem como a evocação de públicos específicos em função destas questões, públicos que se formam a partir da passibilidade, da afetação que sentem em relação ao ocorrido. Os públicos emergem, portanto, da relação entre o agir e o sofrer (DEWEY, 2010).

4. Caracterização de problema público: é reconhecer o acontecimento como uma afetação à sociedade de maneira ampla, demandando ações para combatê-lo e solucioná-lo. Nem sempre os acontecimentos atingem este patamar.

5. Normalização: é o subsequente movimento de acomodação do acontecimento, reduzindo-se o teor de interesse e mobilização em torno dele e sendo absorvido pela cotidianidade. Nesse decrescente,

o acontecimento já não mais suscita o nível inicial de estranhamento e discussão, adequando-se ao ritmo do dia a dia.

O percurso descrito fundamenta a investigação aqui empreendida. Porém, antes de avançar nas constatações sobre o produto televisivo, discuto a seguir, brevemente, outros conceitos que embasam o trabalho - em total articulação com a noção de acontecimento: enquadramento e footing.

\section{Enquadramento e footing: os quadros de sentido e posicionamentos dos sujeitos}

Para definir e explicar os acontecimentos que se passam ao nosso redor, estabelecemos grades de sentido a nortear nossa percepção e permitir uma experiência cognoscível do mundo. Os quadros de sentido por nós acionados se formam na esfera do social, ou seja, são modos de organizar nosso universo de reconhecimento a partir da formatação na coletividade. Portanto, 
A maneira como os organizamos, e como esses quadros são compostos e hierarquizados, tem a ver com nossa experiência pregressa, com nossos níveis de aprendizado (capacidade de cognição) - estes também estruturados hierarquicamente. Tais quadros, no entanto, não são construções individuais, mas resultados de nossa inserção na cultura. (FRANÇA, 2012, p. 48)

Os enquadres foram primeiramente elaborados por Gregory Bateson e reelaborados por Erving Goffman. Já o conceito de footing demonstra um alargamento destes sentidos e se refere aos posicionamentos assumidos pelos participantes numa troca interativa. Tais posicionamentos podem se alterar e estão relacionados a aspectos socioculturais. O footing é uma espécie de desdobramento dos enquadres numa situação comunicativa, fazendo parte da sociolinguística interacional. Segundo Goffman (1998), footing é o posicionamento ou projeção social dos participantes no processo interativo. Para ele, tal posicionamento é mutável e envolve a incursão de novos quadros na dinâmica. Quando utiliza o conceito de footing, Goffman considera que ele melhor explicita o envolvimento dos participantes sem reduzi-los a falante ou ouvinte - o que implicaria a dimensão do som, quando, de fato, todo o contexto interativo é significativo para identificar os papéis assumidos e reconfigurados pelos sujeitos mediante a dinâmica interativa.

Segundo Mendonça e Simões (2012), amparados nos postulados de Goffman, o conceito de footing é construído e transformado com base nos participantes de uma situação interativa, relacionado diretamente aos enquadres dos acontecimentos. Os autores afirmam que "Footing é a expressão usada por Goffman para nomear o posicionamento dos sujeitos em determinada situação. Uma transformação nessa postura implicará alterações no modo como a situação em questão é definida" (MENDONÇA; SIMÕES, 2012, p. 190). Ao relacionar footing e enquadramento, Mendonça e Simões (2012) destacam que estes conceitos são dinâmicos e sua apreensão deve ser processada a partir da situação na qual os sujeitos interagem.

No caso deste trabalho, a situação interativa investigada é o discurso da mídia televisiva, na esfera do telejornalismo. Os discursos midiáticos jornalísticos são capazes de acionar diferentes matizes dos sujeitos postos em cena e, 
assim, deixar emergir footings que se reorganizam em função da própria lógica da negociação interativa. No caso em questão, por meio dos procedimentos típicos do gênero telejornalístico, nos deparamos com posicionamentos dos envolvidos no caso João de Deus, que ora reforçam o lugar do médium como autoridade espiritual, ora refutam esta alcunha. Em relação aos outros atores envolvidos no curso da interação telejornalística, distintos footings são acionados conforme os intentos da mídia em referendar julgamentos (como, por exemplo, sacralizar o lugar de culpado do médium, acionando uma filha que denuncia o pai) e assumir posturas na dinâmica comunicacional. Por meio de seus discursos, valores morais convocados e fragmentos de falas que confere aos atores envolvidos na cena comunicativa, a mídia televisiva torna-se capaz de acionar footings e (re)posicionar os atores imersos na dinâmica comunicativa a partir de seus jogos de interesse, com base em suas lógicas organizacionais e demandas empresariais.

A produção televisiva, destacando-se aqui o telejornalismo, não só aciona footings como reorienta os quadros de sentido em torno de determinado acontecimento. A descrição de um acontecimento, por exemplo, refere-se aos quadros de sentido convocados para caracterizá-lo. Numa espécie de moldura, o acontecimento é identificado a partir de um arsenal de conceitos, valores e aspectos reveladores da sociedade que o circundam. Por isso, as contribuições de Gregory Bateson (2002) e Erving Goffman (1998) são basilares para a compreensão desse conceito. Goffman (1998) define os quadros como elementos de organização que direcionam acontecimentos sociais e nosso nível de engajamento subjetivo em relação a eles, tomados numa perspectiva situacional. Os enquadramentos nos permitem lidar com as ocorrências dentro de um universo reconhecível, um cômputo de inteligibilidade que nos faz identificar a situação, os sujeitos envolvidos, as expectativas levantadas e as ações esperadas em torno dele. Os quadros de sentidos (frames) organizam as interações vividas em sociedade e estão sempre situados num determinado contexto sociocultural, partilhado por uma coletividade. 
Pressuponho que as definições de uma situação são elaboradas de acordo com os princípios de organização que governam os acontecimentos pelo menos os sociais - e nosso envolvimento subjetivo neles; quadro é a palavra que uso para me referir a esses elementos básicos que sou capaz de identificar. Esta é a minha definição de quadro. Minha expressão "análise de quadros" é um slogan para referir-me ao exame, nesses termos, da organização da experiência. (GOFFMAN, 2012, p. 34)

Não se trata aqui de um alinhamento à perspectiva adotada por Mouillaud (2002), na qual o acontecimento é uma espécie de enquadramento que se modela na mídia ao formato da informação, sendo construído pela mídia em função de seus modos de publicização e não por seu caráter singular. Não é também uma aproximação ao que Charaudeau (2006) entende por acontecimento midiático, sempre construído conforme seu potencial de atualidade, socialização e imprevisibilidade. Alinho-me a Quéré (2005) para a análise do acontecimento em torno da celebridade religiosa João de Deus.

\section{João de Deus: a imagem pública de uma celebridade religiosa}

João Teixeira de Faria é um famoso médium brasileiro que fundou em Abadiânia (interior de Goiás) a Casa Dom Inácio de Loyola, uma espécie de reduto espiritual para tratamentos mediúnicos. Nascido em Cachoeira de Goiás e pai de dez filhos, desde a infância manifestou, segundo relatos, dons da mediunidade e a capacidade de "receber bons espíritos", que o auxiliam na execução de curas. Com projeção internacional, o médium de 78 anos é popularmente conhecido como João de Deus (ou, no inglês, John of God), já atendeu personalidades famosas (como Xuxa) e políticos (como Dilma Rousseff) e, além da Casa de Dom Inácio, mantém a Casa da Sopa e a Casa do Banho, também localizadas em Abadiânia, para atendimentos a pessoas carentes.

As ações de caridade de João Teixeira de Faria e os dons mediúnicos promoveram sua visibilidade pública. A conformação da imagem pública de um indivíduo pode se dar a partir de diferentes campos sociais e, no caso de João de Deus, é no campo religioso que se instaura sua fama, projeção social e reconhecimento. Esta imagem pública, no entanto, não é um elemento estanque na 
biografia dos indivíduos e pode ser atualizada, revisitada, contestada, incrementada ou atacada. Por isso, nessa chave de compreensão é possível articular a imagem pública de uma celebridade (religiosa, no caso) com os acontecimentos que a envolvem - articulando, aqui, celebridade e acontecimento como ferramentas para investigação comunicativa.

Segundo França e Simões (2014, p. 1064), "o processo de construção das celebridades não é um fenômeno recente. Desde a Antiguidade, membros das elites políticas e religiosas buscam conquistar e manter uma distinção em relação aos outros". Rojek (2008) sugere a existência de três demarcadores de status das celebridades: conferida, adquirida e atribuída. Adaptando a linha de raciocínio aberta por esse autor, França e Simões (2014, p. 1065) indicam que o surgimento de celebridades no cenário contemporâneo vincula-se às seguintes tipologias:

ocupação de posição de prestígio ou proximidade com essa posição (ocupar um cargo de destaque, ser seu parente ou alguém muito ligado); possuir atributos ou primar por um desempenho exemplar em alguma atividade; estar inserido em um acontecimento significativo.

João de Deus seria tributário de dons e capacitado a exercer ações exemplares, de relevante destaque, no tocante a curas espirituais, o que o alçou à condição de celebridade religiosa - reconhecido internacionalmente.

Etimologicamente, o termo celebridade ${ }^{2}$ conota fama, celeridade, estar aglomerado. "As raízes latinas indicam um relacionamento no qual uma pessoa é identificada como possuindo singularidade, e uma estrutura social na qual a característica da fama é fugaz" (ROJEK, 2008, p. 11). Famoso e singular, João Teixeira de Faria construiu seu caráter de celebrização em torno da mediunidade, apresentando-se como detentor de uma forte ligação com o plano espiritual e responsável por incorporação de médicos já falecidos para realização de curas.

Uma celebridade, no entanto, não se constrói exclusivamente pelas potencialidades midiáticas, ao passo que também é inegável o papel dos meios 
na projeção e novos modos de circulação de sentidos em torno destas figuras públicas. "Definidos por Rojek (2008) como consequência da queda dos deuses e da ascensão de sociedades seculares e democráticas, os célebres são vistos como uma busca por consolo, sabedoria e felicidade" (SIMÕES; FERREIRA, 2015, p. 77). João de Deus pode ser entendido como uma celebridade religiosa e em torno de seu nome circulam sentidos simbólicos ligados ao universo do misticismo, do transcendental, das curas espirituais, da fé no sobrenatural. A fama singular deste homem atravessou fronteiras e permeou outros países, de modo especial a Austrália, onde inúmeros indivíduos, após visitar o Brasil, carregam consigo as experiências e ritos religiosos vistos e vividos na Casa de Dom Inácio, adaptandoos aos seus contextos locais (ROCHA; VASQUEZ, 2014) e globalizando as relações entre saúde e religião (ROCHA, 2015). Quando as acusações contra o médium vêm à tona, emerge um poder de afetação imediato, instaurando um cenário de controvérsias: um homem de fé ou um homem do crime?

\section{O acontecimento João de Deus}

Os questionamentos levantados pelo caso João de Deus irromperam imediatamente pelos meios de comunicação e reverberaram durante semanas até mesmo na mídia internacional. A potência do acontecimento, responsável por desencadear debates não só em torno das lógicas da fé, como também nas penas e consequências para crimes de abuso sexual, são os motivadores para o detalhamento apresentado a seguir, tecendo em cada tópico uma das fases de investigação de um acontecimento: descrição; narrativização e estabelecimento de intriga; pano de fundo pragmático; o problema público; e a normalização do acontecimento.

\section{Descrição do acontecimento}

Para analisar o acontecimento João de Deus, coletei três edições do dominical Fantástico, como já explicitado. Num primeiro momento, atento ao caráter inaugural do acontecimento (QUÉRÉ, 2005), o que desponta em torno do caso é sua irrupção 
simbólica inesperada, o alto grau de desorganização da imagem pública do médium e a aparente contradição entre espiritualidade e os crimes cometidos pelo homem. O "escândalo", como é enquadrado na primeira edição, irrompe, e os primeiros quadros de sentido acionados para defini-lo são "abuso sexual" e "crime". Essas expressões permanecem no âmbito das tipificações do acontecimento, mas, à medida que novas denúncias são incorporadas aos depoimentos iniciais, outros quadros são levantados para o caso, avançando em relação ao tipificador "crime", de tom genérico, para demarcações empíricas e concretas: "estupro", "estupro de vulnerável", "violência contra a mulher". Estes tipificadores, vale frisar, foram acionados por agentes públicos do Estado, advogados, membros das equipes de investigação, autoridades envolvidas diretamente no caso (policiais, delegados) e profissionais da área da saúde (médicos, psicólogos).

Surgidos em todas as edições coletadas, esses caracterizadores buscavam demarcar as acusações em duas importantes frentes: de ordem jurídico-legal e de ordem médico-psicanalítica. Enquanto autoridades enfatizavam os sentidos criminológicos do acontecimento e as consequências físicas e psicológicas sobre as vítimas, as mulheres, por sua vez, não utilizavam tais terminologias para definir e enquadrar o que vivenciaram. "Cura", "limpeza espiritual", "tratamento" eram os definidores que elas empregavam quando descreviam as ações do médium, palavras que, segundo elas, João de Deus utilizava quando praticava os abusos. A associação dos abusos a termos de cunho espiritual-religioso denota a intencionalidade do médium de sacramentar o ato criminoso sem gerar suspeitas ou dar abertura para acusações, indicando seu poderio místico-religioso.

Na busca por organizar os quadros de sentido, na primeira edição, tão logo emerge o caso, o programa ouve uma autoridade religiosa para posicionar a figura de João Teixeira de Faria. A fonte ouvida é a vice-presidente da Federação Espírita Brasileira, Marta Antunes, que afirma: "Qualquer tipo de abuso, ele escapa do campo da religião e tem que ir pro campo da justiça. Nem todo mundo que é médium, é médium espírita. Médium espírita é regido por comportamentos morais e éticos muito firmes". Como se vê, o posicionamento de João de Deus 
enquanto "médium espírita" é refutado pela entidade federativa a fim de reordenar o footing para unicamente "médium". Assim, a instituição religiosa espírita busca sacramentar um distanciamento de suas práticas e ritos em relação a João de Deus. Após esta modalização, em nenhum outro momento há novas alusões ao espiritismo, como havia feito Tadeu Schmidt na abertura de 9 de dezembro de 2018, ao dizer que "João de Deus é um médium bastante conhecido no Brasil e no mundo e há mais de 40 anos mantém uma casa espírita em Abadiânia, Goiás".

Em torno dos posicionamentos conferidos a João Teixeira de Faria, ele é primeiramente descrito por seu papel religioso ("médium", "líder religioso", "homem de Deus", "líder espiritual"), antes mesmo de conhecermos outras camadas de sua biografia. Paulatinamente, outros footings são assumidos por ele ao longo das edições, tais como "pai", "avô" (que remetem ao ambiente doméstico), ou ainda "traficante" e "ditador", pelo caráter das ações que começaram a se revelar sobre ele. É, no entanto, o papel de "médium" que assume maior projeção na narrativa jornalística como um todo, evidenciando a condição de celebridade religiosa que o projetou no cenário midiático, singularizou-o, e em relação a qual se gera a maior gama de conflito (um "homem de Deus" não comete crimes nem é posto sob suspeitas). Em todas as aparições, João de Deus é apenas visualizado, e quase nunca ouvido. Em 9 de dezembro de 2018, somos apresentados visualmente a João de Deus, por meio de imagens de arquivo (algumas delas se repetem ao longo da reportagem), mas sem qualquer declaração do homem. Na edição de 16 de dezembro de 2018, além das imagens de arquivo, ele aparece num vídeo curto quando se entrega à polícia; também num vídeo curto ele pode ser visto/ ouvido em 24 de março de 2019. Na robusta parte das matérias, João de Deus compõe a cena sem se apropriar do espaço de fala diretamente - mesmo que em discursos passados -, mas está em cena por meio de representantes legais (seus advogados).

Outras participantes integram a narrativa e as mulheres assumem papéis significativos no enredo traçado em torno do acontecimento. A maneira como elas surgem em cena é também um forte elemento de caracterização do acontecimento e sua pujança pública. Elas não querem ser identificadas, são mostradas ora de 
costas, ora com rostos encobertos, embaçados, sob sombras, em ambientes escuros, com as vozes distorcidas e irreconhecíveis. O temor, o pavor e a insegurança quanto ao próprio futuro, descortinado sobre seus passados de violência, fazem com que evitem a aparição pública absoluta e sejam posicionadas como "vítimas". Apenas uma mulher, na segunda edição coletada, se apresenta abertamente, porque diz precisar "superar o medo" e estimular outras mulheres a denunciarem as atrocidades.

Nesse momento de descrição do acontecimento, elas não são definidas por suas profissões, ocupações ou outros demarcadores identitários, surgindo apenas como "mulheres" e "vítimas". Por isso, não foram poucas as vezes em que os repórteres as anunciavam como "esta mulher, que não quer ser identificada". Assim, a identidade de gênero era o footing necessário para realçar o teor das falas e substanciá-las. A partir desses posicionamentos, o programa demarcou, de um lado, um homem atrelado ao universo religioso e, de outro, um conjunto de mulheres que lhe dirigiam acusações fortes de abuso sexual. Assim, começou-se a narrativização do caso.

Narrativização e estabelecimento da intriga: as controvérsias em torno do médium

A narrativização que o programa instaura é mais bem evidenciada quando se completa o ciclo das três edições analisadas. Com a reportagem de 24 de março de 2019, um passado "tenebroso" de João de Deus é mostrado publicamente, referendando o futuro esperado para o médium: a punição. É, inclusive, no reforço ao passado que a defesa tenta atuar ao dizer que "há mais de 40 anos, ele atua fazendo o bem", de modo a evocar sentimentos de benevolência e caridade no agir de João de Deus.

As controvérsias instauradas em torno de João de Deus são fortemente levantadas na segunda edição em análise (16 de dezembro de 2018), quando a atração demarca sentidos e posicionamentos para os sujeitos a partir da relação que assumem com o médium e as opiniões que evocam sobre ele. A dicotomização do acontecimento tem largada dentro da própria família de João Teixeira de Faria, visto que não há unidade de apoio entre seus filhos e netos. É nesse momento que o programa evidencia a intriga central, posicionando, de um lado, uma das 
filhas, que acusa o pai de abuso sexual e estupro, e de outro, as filhas que estão convencidas da inocência do pai. O programa concomitantemente aciona dois footings, posicionando dois conjuntos de valores para João de Deus: de um lado, o "maquiavélico, dominador, sedutor", nas palavras da filha mais velha, Dalva Teixeira; de outro, o pai, "bondoso", "inocente", que está sendo "vítima de um complô", como alega a filha Cynthia Teixeira. De um lado uma filha que diz não enxergá-lo como pai, mas "como um homem que roubou minha vida, minha infância, meus filhos"; de outro uma que, tal qual diz o repórter, "confia cegamente no pai" e afirma que "uma pessoa que faz tanto bem, de repente vira um monstro dessa forma. Eu não acredito". Nesses casos, o acionamento do footing "pai" é feito tanto para exaltá-lo quanto para condená-lo, para recriminar e condenar ações não condizentes com tal papel (o caso de Dalva), bem como para defender o papel por ele desenvolvido (o caso de Cynthia), demonstrando a sobreposição de quadros e valores. Esta é uma das assimetrias mais latentes na atração, pois lança luz sobre a rede de contatos mais próxima do acusado - a família - e, dada a divisão, concretiza a força das acusações e potencializa novos desdobramentos para o acontecimento.

Além da família dividida, o programa destaca que a cidade de Abadiânia também se polarizou, e o conjunto de acusações "deixou perplexa uma cidade inteira", uma "Abadiânia dividida". De um lado, os defensores irrestritos do médium, que não acreditam nas acusações; de outro, os que se veem perplexos com as notícias, reconhecendo que "ele tem que pagar pelo que fez" e "ser riscado das nossas vidas". No âmbito das narrativas, o enredo evidenciou assimetrias e disparidades entre os sujeitos envolvidos e distintos acionamentos de quadros para argumentar seus pontos de vista sobre o médium.

Pano de fundo pragmático

O caso João de Deus provocou reações das mais variadas ordens, mobilizando sentimentos e anseios populares alicerçados em nossa cultura social. Distintos públicos podem ser pensados como diretamente atrelados a tal acontecimento - 
como o das mulheres que já sofreram abusos semelhantes -, mas mereceram destaque dois públicos em especial: o de religiosos e o de afetados economicamente pelo caso. Apesar da proliferação de acusações, muitos entrevistados mantiveram a firme opinião de defesa do médium, notadamente alguns de seus familiares e "fiéis", "seguidores" da Casa de Dom Inácio posicionados como um importante público em torno da controvérsia. Essa polarização, além de caracterizar o teor de narrativização do acontecimento, revela um quadro de sentido constitutivo de nossa sociedade também considerado para a formação de tais opiniões: a religiosidade. Acionando discursos como "eu tenho fé no senhor João [de Deus]", "eu não acredito que ele tenha feito nada disso", muitas pessoas se recusavam a aceitar quaisquer possibilidades de ferir a imagem pública de João Teixeira de Faria, tomando como argumento de defesa sua crença irrestrita no médium e, para tal, acionando a fé e a espiritualidade como recursos inegociáveis.

O teor das acusações divide os "fiéis" de João de Deus porque o acontecimento não diz respeito apenas a legalidade dos depoimentos, mas se refere ao universo simbólico de valores que tais sujeitos acionam quando falam do médium. Para os que o defendem, romper com a ordem até então instituída é negar a religiosidade que os conforma, desacreditar os "milagres" vistos na Casa de Dom Inácio e, assim, inevitavelmente abalar suas crenças na religiosidade, espiritualidade e potência da dita celebridade religiosa. Negar sua própria religiosidade é mais grave, ao que parece, do que aceitar acusações de abuso sexual. Tal acontecimento promove, como é típico a todo acontecimento, um profundo corte na continuidade da existência desses sujeitos e compromete a credibilidade de suas próprias crenças.

O outro público destacado pela atração foram os afetados economicamente pelo acontecimento. Como Abadiânia é uma pequena cidade de Goiás, seus rendimentos giram em torno da movimentação na Casa de Dom Inácio, responsável por trazer turistas de todo o mundo e aquecer as finanças locais. Com as acusações, o movimento decresceu fortemente em poucos dias e os efeitos foram sentidos pelos comerciantes. A declaração dada pelo prefeito, que 
diz estar "apavorado com a perda de receitas que o escândalo pode provocar", demarca consequências financeiras do acontecimento, descortinando outro viés não explorado inicialmente. Nesse caso, para o programa, já não bastava refletir sobre as consequências físicas e psicológicas deixadas nas mulheres, mas contextualizar a questão na ordem dos efeitos imediatos para a coletividade e, assim, escancarar um problema público que não envolvia somente as afetadas direta e dolorosamente pelos abusos sexuais.

\section{O problema público deslindado a partir de João de Deus}

As inúmeras autoridades ouvidas ao longo das três edições dão o tom do acontecimento enquanto problema público, por levantar aspectos importantes da luta contra violência sofrida pelas mulheres, contra o estupro, contra os abusos sexuais. Enquadradas como "vítimas" em todas as edições, as mulheres que sofreram violência sexual são inseridas numa rede de quadros em que, em termos médicos, explicitam-se argumentos para justificar o porquê das denúncias não terem despontado imediatamente após sua ocorrência. A fala da psiquiatra resume: "É quase que um instinto de proteção, diante de uma ameaça que você sente que pode ser algo que você não vai ser suficientemente forte pra reagir, você paralisa. Então, isso é bem comum em mulheres vítimas de abuso sexual". Assim, o problema é levado à esfera pública e encadeado como uma situação que demanda cuidados específicos com relação às vítimas.

Pensando por este viés, é pertinente observar que, por mais que seja um debate recente e acalorado na pauta das reivindicações sociais, nenhuma entidade de defesa da mulher foi ouvida pelo programa em qualquer das edições. Orientações sobre como se comportar, reagir e combater ações de cunho violento, de abuso sexual, não foram transmitidas pelo Fantástico, tampouco indicações de quais órgãos públicos procurar, a quais autoridades recorrer. Em síntese, o problema público é identificado pela atração, que o reconhece como uma situação a despertar debates, mas não são tomadas ações no sentido de combater casos similares - algo que um acontecimento 
é capaz de suscitar. As autoridades entrevistadas orientam quem já sofreu os abusos do médium a denunciar, a não temer, a dar declarações à polícia, mas não agem num caráter instrucional de modo a prevenir outros casos por parte de outros sujeitos abusadores.

\section{A normalização do acontecimento}

Quando decorridos mais de três meses das primeiras denúncias contra o médium, o Fantástico trouxe, em março de 2019, novas acusações envolvendo João de Deus. O acontecimento já vivenciava sua fase de normalização, com aparições pontuais na mídia jornalística em intervalos esporádicos e não sequenciais. Com a exibição de 24 de março, no entanto, novas camadas de sentido são acionadas para o caso, e os quadros anteriormente vinculados ao médium são agora acrescidos de novos tipificadores que o posicionam sob outros papéis. "Assassino", "traficante de drogas", "traficante de minério radioativo", responsável por executar "lavagem de dinheiro" e promover "ameaça a testemunhas" são os papéis insurgentes em março, que se complementam aos já difundidos nas edições anteriores, tais como "estupro de vulnerável" e "falsidade ideológica". Todos estes papéis, no entanto, se referem ao âmbito da criminologia e aos valores que tais ações evocam (papéis familiares e/ou profissionais não são acionados na última edição, como o fora o footing "pai" nas edições de dezembro de 2018).

Nesse sentido, além de reavivar o acontecimento, a edição permitiu avançar nas investigações e, retomando o passado do médium, descobrir outras nuances ligadas a seu nome. Somente com base no acontecimento João de Deus relativo aos abusos sexuais, foi possível traçar um passado envolvendo outros crimes graves que não faziam parte do panorama de discussões ligadas ao médium. Criou-se, dessa forma, um passado exclusivamente vinculado a João de Deus e seu histórico de crimes, até então não explorados em narrativas midiáticas. Como o programa demonstra, o contexto dos crimes passados nunca gerou condenações ao médium - que contou com uma rede de apoio para seguir livre, possivelmente 
incluindo autoridades. O passado, nesse caso, ressurge não como rememoração ou celebração do já vivido, mas

[...] nos é restituído, no sentido pragmático de explorar (inquirir) a evenemencialidade do mundo e constituí-lo, ao constituir a memória do mesmo, mas também em função dos critérios jornalísticos e dos frames da imprensa: sínteses, filtragens, exigências retóricas e semânticas, informações jornalísticas disponíveis, imagens, testemunhos filtrados, notícias normalizadas e adaptadas a rubricas e seções, narrativas híbridas (informação, comentário, opinião, etc.) [...]. (BABO-LANÇA, 2012, p. 60, grifo do autor)

Esta convocação ao passado do acontecimento se dá para esclarecê-lo e não para deduzi-lo (ARENDT, 2008), já que o passado emerge para atender o acontecimento e não é o ponto de partida, sendo evocado para explicar o acontecimento presente e situá-lo na rede temporal. Como bem pondera Quéré (2005, p. 61), "quando um acontecimento se produziu, qualquer que tenha sido a sua importância, o mundo já não é o mesmo: as coisas mudaram. O acontecimento introduz uma descontinuidade, só perceptível num fundo de continuidade". Buscando respostas para o acontecimento em torno dos abusos sexuais, emergiu um passado do acontecimento que evidenciou um histórico de impunidade e coronelismo ligados à figura do líder espiritual. Ao deslindar uma rede de ações do médium, por meio de seu jornalismo investigativo, o Fantástico atuou na delimitação dos quadros de sentido e na promoção da conversação pública sobre o caso, reforçando que "o papel dos media é, sem dúvida, decisivo enquanto suportes, por um lado, da identificação e da exploração dos acontecimentos, por outro, do debate público através do qual as soluções são elaboradas ou experimentadas" (QUÉRÉ, 2005, p. 22).

Como todo acontecimento situa uma rede de temporalidades em torno de si, não se pode negar o passado impune de João Teixeira de Faria. Mas, da mesma forma, não se pode negar que o futuro prospectado aparentemente sinaliza para a consumação da justiça, visto que até hoje o homem "de Deus" segue preso. De fato, após meses da última grande reportagem, o acontecimento João de Deus já não mais domina o noticiário jornalístico nem reverbera em debates cotidianos, tendo efetivamente entrado na fase de normalização. 


\section{Considerações finais}

Quando Hannah Arendt (2008, p. 341) buscou compreender as razões que sustentavam o totalitarismo, ponderou, dentre outros fatores, que o assustador "não é o fato de ser algo novo, mas o fato de ter trazido à luz a ruína de nossas categorias de pensamento e de nossos critérios de julgamento". Transportando o pensamento para o acontecimento aqui discutido, não é somente a "novidade" em si que movimenta o caso, mas o horror de imaginar possíveis argumentos para a defesa de crimes contra a mulher, sustentados pelo viés religioso. Religião e violência são dois quadros de sentidos antagônicos substancialmente acionados ao longo da narrativa jornalística para explicar a efervescência do acontecimento João de Deus em relação aos públicos.

Babo-Lança (2005) afirma que os acontecimentos iluminam seus públicos, tornando-os visíveis e podendo evidenciar problemas de ordem pública responsáveis por intensos debates sociais. O caso João de Deus demonstrou esse potencial hermenêutico para instar conversações sobre temas cadentes à sociedade, como o estupro, a violência sexual contra a mulher, o abuso de poder religioso. Tais denúncias aparecem num momento em que o pano de fundo pragmático da sociedade brasileira enfrenta uma onda conservadora e profundos retrocessos em debates importantes no seio da política institucional. De todo modo, "[... a potencialidade do acontecimento reside no desafio de identificar, através dele, tendências que apontam para a preservação e/ou renovação da vida social" (FRANÇA; LOPES, 2017, p. 76). A imagem pública de João de Deus certamente esteve em debate em inúmeras outras mídias, dada a proporção do caso e, por tal razão, não traçamos qualquer indício de proposta generalista, mas uma abertura ao horizonte de possibilidades que o acontecimento proporcionou, destacando seu poder hermenêutico (QUÉRÉ, 2005) a fim de "captar o poder de revelação desse acontecimento" (ARENDT, 2008, p. 343).

O acontecimento João de Deus não só evocou distintos papéis para o homem, como também demarcou o posicionamento das mulheres que sofreram os abusos. Reforçado pelo binarismo visto na família, a dicotomização enfatizou fortemente as contradições em torno dos footings "pai", "médium" e "abusador/ 
criminoso", bem como dos valores agregados a esses diferentes posicionamentos. No caso das mulheres, o acontecimento evidenciava sua condição de gênero para demarcar o tamanho das agressões e tipificá-las como efetivamente deveriam ser enquadradas: violência contra a mulher. Polarizações foram o eixo de ordem na atração: religião $\times$ violência; médium × abusador; pai $\times$ monstro; "de Deus" × "do crime". Por mais que os desdobramentos do acontecimento não tenham gerado produtos socioculturais de maior projeção - instauração de novas leis, por exemplo a condenação pública do homem "de Deus" referendou que a celebridade religiosa começaria a arcar pelos crimes cometidos e, assim, a punição se configurou num dos quadros de sentido atrelados ao processo de normalização do acontecimento e numa espécie de compensação simbólica para a parcela da sociedade que se indignou com o acontecimento.

\section{Referências}

ARENDT, H. Compreensão e política. In: ARENDT, H. Compreender: formação, exílio e totalitarismo. São Paulo: Companhia das Letras; Belo Horizonte: Editora UFMG, 2008. p. 330-346.

BABO-LANÇA, I. A constituição do sentido do acontecimento na experiência pública. Trajectos, Lisboa, n. 6, p. 85-94, 2005.

BABO-LANÇA, I. Acontecimento e memória. In: FRANÇA, V. R. V.; OLIVEIRA, L. (org. ). Acontecimento: reverberações. Belo Horizonte: Autêntica, 2012. p. 55-65.

BATESON, G. Uma teoria sobre brincadeira e fantasia. In: RIBEIRO, B. T.; GARCEZ, P. M. (org.). Sociolingüística interacional. 2. ed. rev. e ampl. São Paulo: Loyola, 2002. p. $85-105$. 
CHARAUDEAU, P. Discurso das mídias. Tradução: Angela S. M. Correa. São Paulo: Contexto, 2006.

DEWEY, J. Ter uma experiência. In: BOYDSTON, J. A. (org.). Arte como experiência. Tradução: Vera Ribeiro. São Paulo: Martins Fontes, 2010. p. 109-141.

FRANÇA, V. R. V. O acontecimento para além do acontecimento: uma ferramenta heurística. In: FRANÇA, V. R. V.; OLIVEIRA, L. (org.). Acontecimento: reverberações. Belo Horizonte: Autêntica, 2012. p. 39-51.

FRANÇA, V. R. V. O crime e o trabalho de individuação do acontecimento no espaço midiático. Caleidoscópio, Lisboa, v. 10, p. 59-72, 2011.

FRANÇA, V. R. V.; LOPES, S. C. Análise do acontecimento: possibilidades metodológicas. Matrizes, São Paulo, v. 11, n. 3, p. 71-87, 2017.

FRANÇA, V. R. V.; SIMÕES, P. G. Celebridades como ponto de ancoragem na sociedade midiatizada. Revista Famecos, Porto Alegre, v. 21, n. 3, 2014, p. 1062-1081.

GOFFMAN, E. Footing. In: RIBEIRO, B. T.; GARCEZ, P. M. Sociolinguística interacional: antropologia, linguística e sociologia em análise do discurso. Porto Alegre: AGE, 1998. p. 107-148.

GOFFMAN, E. Os quadros da experiência social: uma perspectiva de análise. Petrópolis: Vozes, 2012.

MEAD, G. H. Mind, self and society: from the standpoint of a social behavior. Chicago: University of Chicago, 1934. 
MENDONÇA, R. F.; SIMÕES, P. G. Enquadramento: diferentes operacionalizações analíticas de um conceito. Revista Brasileira de Ciências Sociais, São Paulo, v. 27, n. 79, p. 187-201, 2012.

MOUILLAUD, M. A crítica do acontecimento ou o fato em questão. In: MOUILLAUD, M.; PORTO, S. D. (org.). O jornal: da forma ao sentido. 2. ed. Brasília, DF: Editora UnB, 2002. p. 49-83.

QUÉRÉ, L. A dupla vida do acontecimento: por um realismo pragmatista. In: FRANÇA, V. R. V.; OLIVEIRA, L. de (org.). Acontecimento: reverberações. Belo Horizonte: Autêntica, 2012. p. 21-38.

QUÉRÉ, L. Entre o facto e sentido: a dualidade do acontecimento. Trajectos, Lisboa, n. 6, p. 59-75, 2005.

ROCHA, C. A globalização da cura espírita: biomedicina, João de Deus e seus seguidores australianos. Tempo Social, São Paulo, v. 27, n. 1, p. 95-115, 2015.

ROCHA, C.; VASQUEZ, M. O Brasil na nova cartografia global da religião. Religião e Sociedade, Rio de Janeiro, v. 34, n. 1, p. 13-37, 2014.

ROJEK, C. Celebridade. Rio de Janeiro: Rocco, 2008.

SIMÕES, P. O acontecimento e o campo da comunicação. In: FRANÇA, V. R. V.; ALDÉ, A.; RAMOS, M. C. (org.). Teorias da comunicação no Brasil: reflexões contemporâneas. Salvador: Edufba, 2014. p. 173-196.

SIMÕES, P. O acontecimento Ronaldo: a imagem pública de uma celebridade no contexto social contemporâneo. 2012. Tese (Doutorado em Comunicação Social) Universidade Federal de Minas Gerais, Belo Horizonte, 2012. 
SIMÕES, P.; FERREIRA, J. S. Acontecimento, celebridade e carisma: uma análise da imagem pública do Papa Francisco. Comunicação Midiática, Bauru, v. 10, n. 1, p. $70-83,2015$.

submetido em: 4 ago. 2019 | aprovado em: 2 out. 2019 